\title{
Un hommage d'historiens de l'Université de Rouen à Marc Bouloiseau (1915-1998)
}

\author{
Claude Mazauric
}

\section{QpenEdition Journals}

\section{Édition électronique}

URL : https://journals.openedition.org/ahrf/1838

DOI : 10.4000/ahrf.1838

ISSN : 1952-403X

Éditeur :

Armand Colin, Société des études robespierristes

\section{Édition imprimée}

Date de publication : 1 décembre 2000

Pagination : 171-172

ISSN : 0003-4436

Référence électronique

Claude Mazauric, « Un hommage d'historiens de l'Université de Rouen à Marc Bouloiseau

(1915-1998) », Annales historiques de la Révolution française [En ligne], 322 | octobre-décembre 2000, mis en ligne le 22 mars 2006, consulté le 23 avril 2022. URL : http://journals.openedition.org/ ahrf/1838; DOl : https://doi.org/10.4000/ahrf.1838

Ce document a été généré automatiquement le 23 avril 2022.

Tous droits réservés 


\title{
Un hommage d'historiens de l'Université de Rouen à Marc Bouloiseau (1915-1998)
}

\author{
Claude Mazauric
}

De 1930 jusqu'à sa disparition, Marc Bouloiseau s'est distingué comme un historien majeur de l'histoire de la Révolution française et son œuvre occupe une place, au sens propre incontournable, dans le champ historiographique contemporain consacré à la Révolution. Qui pourrait l'oublier Assurément pas les historiens de Rouen qu'il aura en particulier beaucoup soutenus et aidés de ses conseils

2 Massive et diverse, l'œuvre de Marc Bouloiseau est toujours présente à l'horizon de nos recherches autant qu'à leur fondement. Pionnière, sa thèse sur la vente des biens nationaux, dits de "seconde origine dans le District de Rouen, a illustré après 1930 le tournant de l'historiographie mathiéziste vers le social, entendu comme l'étude des transferts socialement différentiels des plus-values produites à l'occasion de la grande mutation révolutionnaire. Érudite et novatrice, l'édition des Cahiers de doléances du Bailliage de Rouen puis de Gisors, constitue un corpus dont l'exhaustivité et la qualité de l'apparat critique font toujours l'admiration des utilisateurs. Que dire d'autre part de l'immense et permanente participation de Marc Bouloiseau, en collaboration avec Albert Soboul et Jean Dautry sous la houlette de Georges Lefebvre, à l'édition des volumes de Discours dans les Euvres de Maximilien Robespierre que la Société des études robespierristes vient de rééditer Bouloiseau y fait page après page la démonstration de son incomparable connaissance des fonds nationaux d'archives et des séries de journaux conservés à la Bibliothèque nationale ou à la Bibliothèque historique de la Ville de Paris. Ses manuels (La République jacobine au Seuil - 1972 -, les pages rédigées par lui dans Le XVIIIe siècle de Ernest Labrousse et Roland Mousnier paru dans la collection Histoire générale des civilisations aux P.U.F. sous la direction de Maurice Crouzet en 1959), sa courte mais dirimante biographie de Robespierre dans "Que sais-je, d'autres ouvrages encore, ont contribué à former des générations d'étudiants par lui avertis des élans comme des tensions et contradictions de la "geste révolutionnaire 
ainsi qu'il aimait à dire. Les innombrables études, communications aux congrès des Sociétés savantes, ses articles et comptes rendus de lecture dans les A.H.R.F. ont initié les chercheurs, alors jeunes, aux pérégrinations complexes qu'il leur a fallu entreprendre dans le maquis des sources et de l'historiographie révolutionnaire, les préparant ainsi à mieux servir leurs cadets.

Mais Marc Bouloiseau eut aussi la passion de l'organisation collective de la recherche. Secrétaire, toujours en déplacement, de la "Commission Jaurès, il n'eut de cesse de vouloir relancer l'activité de ses comités départementaux que la guerre puis les difficultés consécutives avaient souvent mis en sommeil. C'est dans ce cadre, autant que dans celui de la Société des études robespierristes, que me fut donnée l'occasion de le connaître et de l'apprécier dès 1958. À partir de 1961, avec l'aide d'un grand préfet gaulliste, P. Chaussade, avec l'appui de Jean Vidalenc, professeur d'histoire contemporaine à l'Université de Caen et qui allait opter pour celle de Rouen après sa création en 1965, et bientôt avec la collaboration active du nouveau directeur des archives de Seine-Maritime, F. Burckard, et de toute son équipe, Marc Bouloiseau fit appel aux historiens nouveaux venus et résidant à Rouen pour redonner vie et dynamisme au Comité départemental de Seine-Maritime d'histoire de la Révolution française, devenu en 1986 Comité régional de Haute-Normandie ce comité a constitué le socle véritable sur lequel s'est bâtie et a prospéré l'histoire de la Révolution française dans l'espace haut-normand, histoire à laquelle l'institution universitaire rouennaise puis havraise, ont donné ses lettres de noblesse. C'est assez dire que le souvenir de Marc Bouloiseau demeure et demeurera vivant dans la mémoire des historiens normands qu'il a beaucoup contribué à éclairer de son savoir et pour lesquels, jusqu'au soir de sa vie, il a montré un vif et affectueux intérêt comme le montre la donation qu'il leur fit de la "part normande de sa bibliothèque personnelle.

4 Assurément peu récompensé de son vivant malgré son zèle inusable qui aurait mérité plus de considération de la part de l'Alma Mater, Marc Bouloiseau aura eu la satisfaction de se savoir estimé de ses pairs et entouré de la gratitude de toutes les générations de chercheurs qui, depuis Mathiez jusqu'à nous, se sont employés à mieux connaître la Révolution française, ses acteurs, son mouvement.

Saluons la mémoire d'un historien qui fut un chercheur d'envergure et un pilote de premier ordre. 